\title{
Os sentidos da pesquisa sobre corrupção
}

\section{Sílvio César Zákhia Marani'}

Mozar José de Brito²

Gustavo Costa de Souza ${ }^{1}$

Valéria da Glória Pereira Brito²

1 Universidade Federal de Lavras / Programa de Pós-Graduação em Administração Pública, Lavras / MG — Brasil

${ }^{2}$ Universidade Federal de Lavras / Departamento de Administração e Economia, Programa de Pós-Graduação em Administração,

Lavras / MG — Brasil

Este artigo pretende traçar um panorama geral sobre as discussões acumuladas em torno da corrupção, identificando e agrupando as principais ocorrências relacionadas com ela na pesquisa científica. Os textos encontrados durante o processo de revisão de literatura revelam o caráter heterogêneo e assimétrico da produção científica sobre o tema. Do parco ou quase inexistente número de artigos dedicados exclusivamente à revisão de literatura sobre a corrupção até a infinidade de textos que atacam suas causas, efeitos e percepção, o tema é abordado com interesses diferentes no meio científico. Nosso artigo pretende prestar uma contribuição aos estudos de administração pública ao identificar os sentidos das pesquisas sobre corrupção e organizá-los em seis grupos ou eixos temáticos.

Palavras-chave: corrupção; revisão de literatura; eixos temáticos; pesquisa científica; Brasil.

\section{Los sentidos de la investigación sobre corrupción}

En este artículo se pretende dar una visión general de los debates acumulados alrededor de la corrupción, identificando y recogiendo las principales ocurrencias en la investigación científica. Los textos encontrados durante el proceso de revisión de la literatura revelan el carácter heterogéneo y asimétrico de la literatura científica sobre el tema. De la escasa o casi inexistente cantidad de artículos dedicados exclusivamente a la revisión de la literatura sobre la corrupción a la multitud de textos que atacan sus causas, efectos y percepción, el tema se aborda con diferentes intereses en la comunidad científica. Nuestro artículo pretende hacer una contribución a los estudios de la administración pública identificando los sentidos de la investigación sobre la corrupción y organizándolos a partir de seis grupos o ejes temáticos.

Palabras clave: corrupción; revisión de literatura; ejes temáticos; investigación científica; Brasil.

\section{Meanings in research on corruption}

This article aims to give an overview of the accumulated discussions about corruption, identifying and gathering its main occurrences in scientific research. The texts found during the literature review process reveal the heterogeneous and asymmetrical character of scientific literature on the subject. From the scarce or barely existing number of articles devoted exclusively to the literature review on corruption to the multitude of texts that tackle its causes, effects and perception, the subject is approached with different interests in the scientific community. This article aims to contribute to Public Administration studies by identifying the senses of research on corruption and organizing them into six groups or thematic axes.

Keywords: corruption; literature review; thematic axes; scientific research; Brazil. 


\section{INTRODUÇÃO}

Alçada à condição de um dos maiores inimigos das organizações, a corrupção tem reafirmado, no mundo contemporâneo, sua vocação para desafiar a pesquisa científica a compreendê-la.

Neste trabalho, pretendemos desvendar as direções em que os estudos sobre corrupção acontecem. Ele não é, portanto, um esforço de compreender sua natureza, nem de oferecer uma definição sobre ela, mas de traçar um panorama sobre as discussões acumuladas em torno dessa ideia, identificando e agrupando as principais ocorrências na pesquisa científica.

Dividimos nosso trabalho em três partes. Na primeira parte, explicitamos os procedimentos utilizados no processo de revisão de literatura. Apresentamos os métodos e detalhamos os passos dados em cada fase do levantamento bibliográfico.

Na segunda parte, percorremos os sentidos ou direções da pesquisa. Eles não expressam uma "tendência" nos estudos, como a palavra "direções" poderia sugerir, mas os temas que surgem a partir deles. Esses sentidos, direções ou perspectivas foram nomeados a partir do tipo de preocupação que os textos expressam. Dessa forma é que falamos, por exemplo, em um sentido introdutório, conceitual ou, mesmo, de um sentido que se relaciona com as formas de controle da corrupção.

$\mathrm{Na}$ terceira parte, estabelecemos alguns apontamentos acerca da pesquisa sobre corrupção no Brasil, destacando sua conexão com os estudos no campo da administração pública. Isso foi possível graças aos resultados obtidos na segunda parte. A partir deles, pretendemos desvendar as particularidades da produção bibliográfica no país: o modo como ela se organiza, os principais atores e o estágio em que ela se encontra na administração pública.

Diante desse conjunto de preocupações e conscientes de que nossa diretriz é apresentar um panorama introdutório das pesquisas em corrupção, contribuindo para sua sistematização e para o delineamento de futuras pesquisas no campo, passamos ao seu exame nos tópicos seguintes.

\section{DESVENDANDO OS SENTIDOS DA PESQUISA: PROCEDIMENTOS DE MAPEAMENTO DE LITERATURA SOBRE CORRUPÇÃO}

O interesse da comunidade científica pelo tema da corrupção tem crescido ao longo das últimas décadas. Uma busca na base ScienceDirect revela que no início do milênio publicavam-se cerca de 500 artigos por ano sobre o tema, quantidade que, 10 anos mais tarde, mais que duplicaria para, em seguida, saltar, no início da década, ao número de 1.570 artigos, chegando aos 2.845 registrados ao final do ano de 2015.

Se, de um lado, a presença e circulação do tema em revistas de alto fator de impacto expressam, de fato, um alargamento do interesse de pesquisadores relativamente ao tema da corrupção, de outro lado, elas evidenciam que a ascendência desse movimento nem sempre vem acompanhada de um esforço equivalente de sistematização.

Com o objetivo de oferecer um primeiro arranjo dos estudos sobre corrupção, adotamos em nossa pesquisa procedimentos derivados da combinação entre duas formas de revisão de literatura: o método da revisão de escopo de literatura e o método da revisão integrativa.

Segundo Armstrong e colaboradores (2011), a revisão de escopo oferece uma abordagem estruturada para a coleta de informações, por meio do mapeamento ou recorte da literatura existente sobre um dado tema, sem, contudo, enveredar-se em procedimentos exaustivos de análise e síntese de dados ou na avaliação qualitativa e quantitativa da publicação. Uma de suas grandes vantagens está na capacidade de informar as pesquisas atuais ou futuras na área. 
Rumrill, Fitzgerald e Merchant (2010) argumentam na mesma direção, salientando que a revisão de escopo, além de ser exploratória - isto é, de efetuar o exame da variedade e da natureza de uma dada área de pesquisa, determinando se uma revisão sistemática deve ser realizada —, também sumariza e dissemina a pesquisa, na medida em que o pesquisador a utiliza para identificar lacunas existentes na literatura.

No campo de administração pública e dos estudos organizacionais, segundo Botelho, Cunha e Macedo (2011), a revisão integrativa tem a virtude de pavimentar o intercâmbio entre as pesquisas teóricas e as pesquisas experimentais já realizadas, possibilitando ao pesquisador, mediante a manipulação de critérios específicos, recuperá-las e articulá-las durante o processo de revisão.

No caso deste trabalho, a revisão de literatura envolveu, primeiramente, a delimitação da questão de pesquisa aos sentidos dos estudos sobre corrupção: quais os principais temas tratados pela literatura científica quando o assunto é corrupção?

A seleção da temática e a definição da questão de pesquisa foram acompanhadas, no segundo momento, da busca de artigos nas bases eletrônicas de periódicos e do levantamento de livros e ensaios publicados sobre o tema. Para sua seleção, utilizamos os critérios de autoridade, respeitabilidade e prestígio de que gozam os autores na área da pesquisa sobre corrupção, além da atualidade e permanência de seus estudos, a amplitude com que o conteúdo é por eles tratado, bem como a objetividade e precisão de seus textos. Para o levantamento daqueles, nos servirmos da base eletrônica ScienceDirect, à qual juntamos, posteriormente, consultas às bases Scopus, JSTOR, Web of Science, Spell e Scielo.

A crença de que os sentidos da pesquisa sobre corrupção pudessem ser facilmente alcançados por meio de consultas a revisões de literatura já existentes sobre o tema fez com que nossas buscas iniciais fossem orientadas pelos descritores corruption, review, literature, research e studies. A parca existência desse tipo de material, entretanto, nos obrigou mais tarde a restringi-la ao uso isolado do termo corruption.

A variedade de textos encontrados exigiu um cuidado adicional na seleção dos artigos que pudessem compor os grupos ou eixos temáticos. Eles alternam sua preocupação entre sentidos da pesquisa que:

a) são introdutórios, i.e., compostos de textos que apresentam e problematizam os estudos sobre corrupção;

b) são conceituais e fenomenológicos, ou seja, que se ocupam da definição de corrupção e das formas e casos em que ela se manifesta;

c) são paradigmáticos, na medida em que pretendem introduzir formas de análise e interpretação sobre a corrupção a partir de áreas específicas do conhecimento humano;

d) se ocupam da percepção, causas e efeitos da corrupção;

e) pensam o controle da corrupção; $\mathrm{e}$

f) investigam o tratamento oferecido pela mídia à corrupção.

A classificação dos textos em cada uma das categorias, bem como seu descarte, obedeceu a quatro procedimentos específicos: leitura do título, leitura do resumo ou abstract, leitura das palavras-chave, skimming e comparação do conteúdo do artigo com os sentidos identificados na pesquisa. É evidente que o número final de textos apresentados em cada grupo poderia ser maior do que é, mas pretendemos haver trabalhado com um número suficiente de artigos que pudesse expressar o sentido que o grupo de fato possui. Desse modo, acolhemos aqueles que nos pareceram se adequar mais corretamente aos critérios estabelecidos e excluímos os demais. 
A classificação de um artigo ou livro em um ou outro grupo pode suscitar dúvidas e discordâncias, mas salientamos que as fronteiras entre o tipo de preocupação preponderante nos textos sobre corrupção nem sempre é clara. Embora um artigo ou livro apresente, presumivelmente, um tom conceitual, a resposta que ele dá à pergunta "o que é a corrupção?" pode acabar fornecendo elementos que o façam ser classificado como um texto que trate de paradigmas de interpretação ou até mesmo das causas, efeitos e percepção da corrupção. Dessa forma, a escolha pelo melhor enquadramento nem sempre foi fácil e nem sempre encontrou uma solução satisfatória por meio das palavras-chave.

Conscientes dessas limitações, passamos a apresentar na próxima seção os resultados obtidos com a pesquisa e a classificação dos textos.

\section{OS SENTIDOS CONSTRUÍDOS PELOS AGENTES DA PESQUISA: PRINCIPAIS GRUPOS, PREOCUPAÇÕES E LACUNAS NA LITERATURA SOBRE CORRUPÇÃO}

O primeiro grupo temático de artigos que tomamos para análise expressa o sentido introdutório da pesquisa sobre corrupção. Ele é composto por textos que oferecem uma apresentação inicial do tema e realizam uma problematização dos seus estudos a partir das principais teorias e discussões sobre a corrupção. A existência de artigos dedicados exclusivamente à revisão de literatura é bastante rara entre eles, de modo que a organização desses estudos se torna uma tarefa importante para futuras pesquisas na área. Entre os textos que recorrem a algum tipo de revisão ou sistematização da literatura estão os de Brei (1996b), Torsello e Venard (2016), Judge, McNatt e Xu (2010), Mény (1996), Biason (2012a) e Filgueiras (2008b).

\section{QUADRO 1 O SENTIDO INTRODUTÓRIO DA PESQUISA SOBRE CORRUPÇÃO}

\begin{tabular}{l|l|l}
\hline $\begin{array}{l}\text { Revisão de Literatura } \\
\text { Correntes de pensamento e marcos teóricos }\end{array}$ & $\begin{array}{l}\text { Brei (1996b); Biason (2012a); Filgueiras } \\
\text { (2008b) }\end{array}$ \\
\hline $\begin{array}{l}\text { Estudos antropológicos } \\
\text { Meta-análise }\end{array}$ & $\begin{array}{l}\text { Estudos empíricos sobre as causas e os efeitos da e Venard (2016) } \\
\text { corrupção }\end{array}$ & $\begin{array}{l}\text { Tudge, McNatt e Xu (2010) } \\
\text { Outros }\end{array}$ \\
\hline Evolução dos estudos sobre corrupção & Mény (1996)
\end{tabular}

Fonte: Elaborado pelos autores.

O artigo de Brei (1996b) concentra-se na revisão das principais correntes de pensamento sobre a corrupção, agrupando-as em quatro conjuntos: os textos que definem a corrupção do ponto de vista do mercado, os que levam em conta o interesse público, os que a conceituam a partir da opinião pública e aqueles que a reconhecem sob o ponto de vista legal. Considerando-se a escassez de revisões, este é um ponto de partida para pensarmos as definições sobre a corrupção, ainda que ele não contemple perspectivas surgidas na primeira e na segunda década dos anos 2000, como a antropológica, 
revisitada no texto de Torsello e Venard (2016). Em seu artigo, os autores realizam uma revisão da literatura no campo da antropologia, explicitando como uma nova compreensão da moralidade pode contribuir para os estudos sobre corrupção. A ideia defendida pelos autores é a de que a compreensão sobre a corrupção deve ser devolvida ao contexto em que ela surge, não sendo examinada a priori, nem de maneira definitiva, como algo negativo. Judge, McNatt e Xu (2010) conduzem, por sua vez, um processo de mapeamento da literatura que se apoia no estudo de meta-análise de 42 estudos empíricos, por meio do qual classificam a produção científica sobre corrupção em três grandes áreas: a política ou legal, a econômica e a sociocultural. Mény (1996) presta sua contribuição ao explicitar como o fenômeno da corrupção ganhou proeminência ao longo do tempo e como, ao se tornar mais complexo, deu origem a diferentes modos de interpretação. Biason (2012a) traça uma revisão sobre as principais teorias da corrupção (personalista, funcionalista, legalista, econômica, política etc.), enquanto Filgueiras (2008b) retoma seus marcos teóricos, especialmente aqueles que estão na base das visões neoinstitucionalistas e da teoria da modernização.

Parte dos esforços de pesquisa sobre o tema da corrupção está voltada, também, à sua definição e à apresentação de suas formas, tipos ou práticas. Chamamos a esse sentido de conceitual e fenomenológico. O grupo de artigos que possui essa preocupação recebe as contribuições de Williams (1999), Philp (1997), Johnston (1996), Silva (1994), Filgueiras (2006), Agatiello (2010), Ribeiro (2000), Carvalho (2008), Pinto (2011) e Furtado (2015).

\section{QUADRO 2 O SENTIDO CONCEITUAL E FENOMENOLÓGICO DA PESQUISA SOBRE CORRUPÇÃO}

\begin{tabular}{l|ll}
\hline & Dificuldades de definição & Williams (1999) \\
\hline Conceito & Noções clássicas e modernas & Johnston (1996); Silva (1994) \\
& Corrupção como síndrome & Johnston (2005) \\
& Corrupção como transgressão & Carvalho (2008) \\
\hline Nolítica (instrumento de poder) ou econômica & Agatiello (2010) \\
(finalidade)? & Philp (1997); Filgueiras (2006) \\
\hline Política & Ribeiro (2000) \\
\hline Casos e Práticas & Forma de governar & Pinto (2011) \\
& Órgãos e agentes da administração pública & Furtado (2015)
\end{tabular}

Fonte: Elaborado pelos autores.

Williams (1999) enfatiza a necessidade de nos concentrarmos na definição e refinamento do conceito em razão da diversidade de estudos existentes sobre as causas, consequências e controle da corrupção. $\mathrm{O}$ autor examina a evolução do conceito nas ciências sociais contemporâneas e assegura que eles expressam mais frequentemente as causas que dão origem à corrupção do que a corrupção 
ela mesma. Philp (1997) denuncia as dificuldades surgidas na determinação da natureza política da corrupção, dos seus limites e de suas consequências no âmbito institucional. Johnston (1996) problematiza essa dificuldade apostando na reconciliação entre as abordagens clássicas e modernas sobre a corrupção. O pensamento revelado pelo autor está longe da formulação atingida quase uma década mais tarde ao publicar Syndromes of corruption. Nesta obra, Johnston (2005) concebe a corrupção como uma espécie de "síndrome", cuja origem está no modo como as pessoas trocam poder e riqueza. De acordo com o autor, podemos identificar ao menos quatro tipos dela: a dos mercados de influência, a dos cartéis de elite, a das oligarquias e clãs, e a dos servidores "magnatas". Embora devedora do contexto liberal, a abordagem realizada por Johnston (2005) demonstra originalidade ao pensar os problemas sistêmicos de corrupção. O texto de Silva (1994) retoma a tentativa de definição funcional da corrupção e, embora se vincule às formas mais tradicionais de compreender essa prática, é um dos raros esforços realizados na área da administração pública brasileira para pensar o tema. Filgueiras (2006) associa a definição da corrupção à compreensão de suas linguagens e do processo histórico-social que a estabelece, defendendo a prevalência dos princípios éticos e morais para o bom funcionamento das instituições. Agatiello (2010) examina a influência das noções de integridade política, democracia e de dificuldades econômicas na definição do conceito de corrupção. Essas tentativas lançam dúvidas sobre a capacidade de a corrupção ser explicada exclusivamente pelo viés econômico, segundo o qual ela seria não propriamente um instrumento, mas uma finalidade. Ribeiro (2000) reclama a importância de um olhar ampliado sobre o tema, defendendo a combinação da leitura política com a antropológica, sem a qual somos incapazes de medir os custos sociais da corrupção. Carvalho (2008) tenta pensá-la a partir da lógica da transgressão. Embora a recusa de tomá-la exatamente pela forma como ela é nomeada implique a perpetuação de alguns impasses, o autor desenvolve reflexões sobre a relação do brasileiro com a lei e as práticas de corrupção ao longo da história. Parte dessas práticas são examinadas, também, por Pinto (2011). A autora resgata alguns casos com o objetivo de ilustrar como os tipos de corrupção existentes no sistema político brasileiro (nepotismo, patrimonialismo, clientelismo, por exemplo) estão associados a um modo de exercício do poder que criou raízes no nosso país. Diversos casos de corrupção são analisados, também, por Furtado (2015), que oferece um enfoque intimamente ligado à perspectiva organizacional da administração pública.

Se os exercícios de revisão de literatura e de definição da corrupção não despertam um interesse grande do ponto de vista dos estudos científicos, o mesmo não sucede com os paradigmas de análise e interpretação da corrupção. O sentido paradigmático construído pelos agentes da pesquisa reúne explicações sobre a corrupção a partir das mais diversas áreas do conhecimento humano: da economia, da cultura, da teoria organizacional, da ciência política, da linguística, da psicologia, da filosofia etc. Bardhan (1997) e Aidt $(2003,2009)$ elegem para análise, por exemplo, o paradigma econômico. Eles tentam problematizar o impacto da corrupção na economia por meio de variáveis como eficiência e desenvolvimento. Bardhan (1997) dá ênfase aos argumentos que apostam na relação positiva entre a corrupção e o aumento da eficiência administrativa, enquanto Aidt (2009) percorre o caminho inverso, para provar a ineficiência e os custos impostos ao desenvolvimento pelas práticas de corrupção. Embora seja importante, a discussão econômica parece não encontrar uma saída conciliatória, capaz de afirmar aspectos positivos e negativos da corrupção relativamente ao contexto em que ela aflora. O paradigma cultural, por sua vez, redireciona a discussão para um número surpreendente de temas. Mishra (2006) investiga, por exemplo, a persistência e tolerância à corrupção em determi- 
nadas sociedades, enquanto Barr e Serra (2010) e Miller (2006) avaliam o papel que as normas e os valores sociais exercem sobre a prática da corrupção. Dong, Dulleck e Torgler (2011), assim como Balafoutas (2011), interessam-se por investigar se podemos falar em "contágio" ou transmissão da corrupção. Para isso, se debruçam sobre a relação entre a percepção da corrupção por uma dada sociedade e o engajamento de seus membros em práticas corruptas. No contexto organizacional, destacam-se as interpretações oferecidas sobre a corrupção por Frost e Tischer (2014), que a pensam como uma rotina; por Karmann e colaboradores (2016), que a avaliam em relação à disposição de empreender; e por Rosenblatt (2012), que utiliza a teoria da dominância social para explicar o enraizamento e a perpetuação de práticas de corrupção nas organizações. Trata-se de uma área de estudos promissora, especialmente da perspectiva de tratar a corrupção como uma prática social. Ao seu turno, o paradigma político tenta pensar a corrupção se valendo de discussões que retomam a teoria democrática. O principal texto é de Warren (2004), para quem a corrupção, além de expressar uma violação da norma de inclusão democrática, sinaliza para a existência de grave déficit de democracia. Essa análise é, em certa medida, inovadora dentro do campo político em que ela aparece, firmando-se como uma alternativa às abordagens tradicionais. A utilização de outros paradigmas, como o linguístico, desenvolvido no estudo de Machado (2010), reafirma a tentativa de construção de novos olhares sobre a corrupção, retirando-a de campos semânticos mais tradicionais. Esforço equivalente é realizado por Roberts (2015), que oferece uma explicação para a prática da corrupção por meio do paradigma psicológico, apoiado nos estudos que Lacan e Foucault desenvolvem sobre os processos de subjetivação e dos processos psíquicos de atração pela corrupção. Martins (2008) recorre à filosofia para interrogá-la e confrontá-la com as definições presentes no senso comum, ao passo que Avritzer e colaboradores (2008) e Brei (1996a) oferecem ao pesquisador um panorama geral sobre as perspectivas de análise da corrupção.

\section{QUADRO 3 O SENTIDO PARADIGMÁTICO DA PESQUISA SOBRE CORRUPÇÃO}

\begin{tabular}{llll}
\hline Econômico & Eficiência e desenvolvimento & Bardhan (1997); Aidt (2009) \\
\hline & Persistência e tolerância à corrupção & Mishra (2006) \\
\hline $\begin{array}{l}\text { Papel das normas e valores morais sobre a prática de } \\
\text { corrupção }\end{array}$ & Barr e Serra (2010); Miller (2006) \\
\hline $\begin{array}{l}\text { A corrupção é transmitida por "contágio"? A influência } \\
\text { da percepção da corrupção sobre o engajamento de } \\
\text { burocratas no cometimento dessa prática }\end{array}$ & $\begin{array}{l}\text { Dong, Dulleck e Torgler (2011); Balafoutas } \\
\text { (2011) }\end{array}$ & \\
\hline
\end{tabular}




\begin{tabular}{|c|c|c|}
\hline \multirow{3}{*}{ Organizacional } & Rotina & Frost e Tischer (2014) \\
\hline & $\begin{array}{l}\text { Uso ilício do poder (ou disposição para empreender) para } \\
\text { ganhos pessoais }\end{array}$ & Karmann e colaboradores (2016) \\
\hline & Teoria da dominância social & Rosenblatt (2012) \\
\hline Político & Teoria democrática & Warren (2004) \\
\hline Linguístico & Análise semântica & Machado (2010) \\
\hline Psicológico & Processos de sujeição e atração psíquica pela corrupção & Roberts (2015) \\
\hline Filosófico & Contraposição ao senso comum & Martins (2008) \\
\hline Outros & $\begin{array}{l}\text { Vertentes de pensamento sobre causas, consequências e } \\
\text { soluções para o problema da corrupção }\end{array}$ & Brei (1996a); Avritzer (2008) \\
\hline
\end{tabular}

Fonte: Elaborado pelos autores.

Com vasta penetração na pesquisa científica, os estudos sobre percepção, causas e efeitos da corrupção constituem um sentido especial entre os demais. Uma obra clássica situada nessa área é a de Rose-Ackerman (1999). Nela, a autora dirige seu pensamento às causas e consequências da corrupção, examinando-as, especialmente, no campo econômico. Embora os aspectos políticos e culturais também sejam examinados - e expandidos na segunda edição da obra -, eles não repetem o fôlego da análise econômica. A crença da autora na economia como uma ferramenta poderosa de explicação, combinada com sua passagem por instituições como o Banco Mundial, esclarece a apropriação do seu pensamento pela lógica institucional e os motivos pelos quais ela situa o comportamento self-seeking ou rent-seeking na base da corrupção. É contra esse pano de fundo que novos estudos sobre a corrupção, suas causas e efeitos devem se levantar. Contribuições sobre as causas da corrupção podem ser verificadas, ainda, nos artigos de Goel e Nelson (2010), Roman e Miller (2014), Lee e Guven (2013), Sobhani e Bechara (2011) e Theobald (1999).

Entre as causas catalogadas na literatura científica estão: os fatores históricos e geográficos, apresentados por Goel e Nelson (2010), o status e o parentesco, examinados por Roman e Miller (2014), as normas culturais e as questões de gênero, destacados por Lee e Guven (2013), as lesões e disfunções cerebrais, pesquisadas por Sobhani e Bechara (2011), além de características do subdesenvolvimento, como o patrimonialismo, estudadas por Theobald (1999). Observadas à superfície, as causas sugerem alguma diferença, enquanto uma análise profunda delas revela seu pertencimento ao mesmo grupo de textos que confia a causalidade da corrupção à prevalência dos aspectos culturais. Esse é o motivo pelo qual a investigação realizada por Sobhani e Bechara (2011), que descrevem a corrupção como um traço não propriamente cultural, mas biológico do ser humano, soa dissonante. Essa conclusão deve ser revisitada e interrogada, sobretudo pelas consequências éticas que ela traz para a compreensão da corrupção e do livre-arbítrio. 


\section{QUADRO 4 AS CAUSAS DA CORRUPÇÃO, DESCRITAS PELA PESQUISA CIENTÍFICA}

\begin{tabular}{lll}
\hline $\begin{array}{l}\text { Self-seeking/rent-seeking } \\
\text { Fatores históricos e geográficos }\end{array}$ & Rose-Ackerman (1999) \\
\hline Status e parentesco & Roman e Miller (2014) \\
Normas culturais e questões de gênero & Lee e Guven (2013) \\
\hline Lesões e disfunções cerebrais & Sobhani e Bechara (2011) \\
\hline Subdesenvolvimento, práticas patrimonialistas & Theobald (1999)
\end{tabular}

Fonte: Elaborado pelos autores.

Ao falarmos em consequências, devemos levar em conta a existência de um grande número de textos que se propõem a pensar a corrupção por meio de seus efeitos.

Os artigos de Nye (1967) e Petrou e Thanos (2014) oferecem um panorama mais geral dessas discussões, enquanto outros autores, como Budak e Rajh (2014) e Méon e Weill (2010), discutem a existência de efeitos negativos e positivos da corrupção. Tay, Herian e Diener (2014) pretendem estabelecer sua relação com o bem-estar das pessoas, enquanto Praça (2011) avalia seu impacto no desencadeamento de reformas institucionais.

Os estudos que interrogam os desdobramentos da corrupção no campo econômico e institucional possuem forte apelo empírico, e essa é a razão pela qual acabam prevalecendo sobre estudos teóricos da corrupção. Além disso, esses estudos contribuem, frequentemente, para a confusão entre a definição de corrupção e a explicação de suas causas e efeitos.

\section{QUADRO 5 OS EFEITOS DA CORRUPÇÃO, DESCRITOS PELA PESQUISA CIENTÍFICA}

\begin{tabular}{|c|c|c|}
\hline \multirow{5}{*}{ Efeitos } & Discussões gerais & Nye (1967); Petrou e Thanos (2014) \\
\hline & Positivos para os negócios & Méon e Weill (2010) \\
\hline & Negativos para os negócios & Budak e Rajh (2014) \\
\hline & Para o bem-estar das pessoas & Tay, Herian e Diener (2014) \\
\hline & Em reformas institucionais & Praça (2011) \\
\hline
\end{tabular}

Fonte: Elaborado pelos autores. 
Em se tratando do modo como a corrupção é percebida, um amplo campo de estudos na literatura científica surge ao lado do estudo das suas causas e efeitos. Abramo (2005), Olken (2009), Dreher, Kotsogiannis e McCorriston (2007) e Sah (2007) salientam as dificuldades envolvidas na medição das práticas de corrupção, o que torna índices e indicadores de percepção instrumentos pouco confiáveis na descrição desta prática. Poeschl e Ribeiro (2010) dão destaque às diferenças de percepção surgidas em diferentes contextos sociais, locais e globais, enquanto Santos, Guevara e Amorim (2013) avaliam sua relação com o grau de instrução, gênero e idade das pessoas nas organizações privadas. Filgueiras (2009) explora a contradição existente entre valores morais e a prática da corrupção na opinião pública brasileira, explicitando em que medida esse afastamento é determinado pelo modo como percebemos a corrupção. Essa percepção, bem como o papel que ela assume na formação da opinião pública, é estudada por Heidenheimer (1996) por meio dos chamados processos de escandalização.

\section{QUADRO 6 A PERCEPÇÃO DA CORRUPÇÃO, DESCRITA PELA PESQUISA CIENTÍFICA}

\begin{tabular}{|c|c|c|}
\hline \multirow{5}{*}{ Percepção } & Medição e uso de indicadores & $\begin{array}{l}\text { Abramo (2005); Olken (2009); Dreher, } \\
\text { Kotsogiannis e McCorriston (2007); Sah (2007) }\end{array}$ \\
\hline & $\begin{array}{l}\text { Contextos sociais diferentes } \\
\text { (local e global) }\end{array}$ & Poeschl e Ribeiro (2010) \\
\hline & $\begin{array}{l}\text { Contexto organizacional } \\
\text { (idade, gênero e instrução) }\end{array}$ & Santos, Guevara e Amorim (2013) \\
\hline & Opinião pública brasileira & Filgueiras (2009) \\
\hline & Escandalização & Heidenheimer (1996) \\
\hline
\end{tabular}

Fonte: Elaborado pelos autores.

Um dos temas mais cativos surgidos na pesquisa das últimas décadas e que dá forma a outro sentido da pesquisa sobre corrupção é o dos mecanismos de controle. Nele, duas obras merecem destaque: a de Klitgaard (1994) e a de Anechiarico e Jacobs (1996).

Klitgaard (1994) explora em seu livro estudos de caso com o intuito de elaborar, a partir deles, políticas de combate à corrupção. $\mathrm{O}$ autor elabora sua famosa fórmula matemática, em que a corrupção corresponde ao arranjo de variáveis como: monopólio, discricionariedade e accountability. Embora a obra tenha se tornado um clássico da literatura científica, ela se encarregou de difundir uma receita institucional para o combate à corrupção circunscrita a países pobres e em desenvolvimento, fora dos quais pouco sabemos do seu alcance.

Convertida em outro clássico dos estudos anticorrupção, a obra de Anechiarico e Jacobs (1996), assentada sobre a investigação de medidas anticorrupção adotadas no Departamento de Polícia da cidade de Nova York, lida com a ideia segundo a qual os esforços de combate à corrupção podem ser tão danosos quanto a própria corrupção, contribuindo, no limite, para a ineficiência do governo. Apesar da visão polêmica introduzida pelos autores, trata-se de um material que obriga o pesquisa- 
dor da corrupção a cultivar certo ceticismo no estudo das medidas anticorrupção, sopesando seus aspectos positivos e negativos.

Nos periódicos com alto fator de impacto, por sua vez, a discussão sobre o sentido do controle é aprofundada em torno de suas modalidades ou formas de exercício: institucionais, burocráticos, sociais ou democráticos, eletrônicos e midiáticos.

\section{QUADRO 7 AS FORMAS DE CONTROLE DA CORRUPÇÃO, DESCRITAS PELA LITERATURA CIENTÍFICA}

\begin{tabular}{|c|c|c|}
\hline Institucional & $\begin{array}{l}\text { Reformas, estruturas de controle interno e } \\
\text { compromissos éticos }\end{array}$ & $\begin{array}{l}\text { Gong e Wang (2013); Truex (2011); } \\
\text { Rose-Ackerman (2002); Klitgaard (1994); } \\
\text { Anechiarico e Jacobs (1996) }\end{array}$ \\
\hline Burocrático & Ao nível da rua & Filgueiras e Aranha (2011) \\
\hline \multirow[t]{2}{*}{ Social ou Democrático } & Participação social & Warren (2005) \\
\hline & Internet & Lio, Liu e Ou (2011) \\
\hline \multirow[t]{2}{*}{ Eletrônico (TIC) } & Mídias sociais & Bertot, Jaeger e Grimes (2010) \\
\hline & Governo eletrônico & Andersen (2009) \\
\hline Midiático & Liberdade de imprensa & $\begin{array}{l}\text { Camaj (2013); Bhattacharyya e Hodler } \\
\text { (2015) }\end{array}$ \\
\hline
\end{tabular}

Fonte: Elaborado pelos autores.

Entre os controles institucionais, podemos destacar a criação ou reformulação de órgãos encarregados do combate à corrupção, examinada por Gong e Wang (2013) a partir da experiência realizada em Hong Kong; a celebração de compromissos éticos, ressaltada por Rose-Ackerman (2002); e a concessão de melhorias no acesso à educação à população, analisada por Truex (2011). Paralelamente ao controle institucional, temos, ainda, o controle burocrático, que não se manifesta diretamente nas instituições, mas em seu corpo de funcionários. Filgueiras e Aranha (2011) sugerem que o controle efetivo sobre as práticas de corrupção pressupõe a diminuição da discricionariedade dos burocratas ao nível da rua. A perspectiva, embora convidativa do ponto de vista empírico, cria arestas teóricas que necessitavam ser repensadas. A primeira consiste em retomar a relação entre discricionariedade e corrupção: será ela mesma determinante para a prática da corrupção? A segunda consiste em sugerir a persistência da corrupção em estratos mais baixos da hierarquia administrativa, onde ela seria mais expressiva: não estariam os ocupantes de cargos da alta administração expostos a práticas semelhantes, uma vez que gozam de certa liberdade na definição de suas escolhas? Essas questões são importantes e devem ser respondidas para que tenhamos dimensão dos limites das reformas gerenciais no controle da corrupção, especialmente no Brasil. Outra face dos estudos sobre o combate à corrupção aposta no controle social ou democrático. Warren (2005) é um entusiasta dessa ideia e, em seu texto, demonstra como a organização ou empoderamento da sociedade civil e das instituições pode favorecer a accountability e, 
consequentemente, uma política sem corrupção. Essa perspectiva merece ser cotejada com as iniciativas já existentes no campo institucional, a fim de se apurar, mais precisamente, o grau de autonomia e independência que o controle social tem sobre aquele realizado pelas instituições.

Paralelamente ao controle democrático, temos visto crescer o interesse pelas formas eletrônicas de combate à corrupção. Lio, Liu e Ou (2011), Bertot, Jaeger e Grimes (2010) e Andersen (2009) exploram a capacidade dos meios eletrônicos e das ferramentas das tecnologias da informação e comunicação, como a internet, as mídias sociais e o próprio governo eletrônico, em oferecer um contraponto à corrupção. São estudos que reavivam a crença na ressignificação da atividade do controle, estimulando sobretudo a prevenção, em detrimento de ações repressivas.

A última faceta do controle da corrupção, embora pouco explorada na literatura científica, pretende atribuir à imprensa um papel de destaque no combate a essa prática.

Bhattacharyya e Hodler (2015) argumentam que a combinação entre os incentivos à democratização e a liberdade de imprensa representa uma iniciativa importante no combate à corrupção política. Camaj (2013) examina a relação entre liberdade de imprensa e os níveis de corrupção, sugerindo que lugares em que se pratica pouca corrupção são, igualmente, lugares em que a mídia tem maior liberdade para exercer suas atividades.

Essa relação da mídia com a corrupção funda, em alguma medida, um sentido próprio na pesquisa científica. Além do papel desempenhado por ela no controle da corrupção, existe na literatura um interesse por pensar o tratamento oferecido pela mídia a esse tema. Trata-se de textos que focalizam a construção de narrativas sobre a corrupção especialmente a partir dos processos de escandalização e dramatização.

Breit (2010) examina esses processos e desvenda formas de discurso até então não enunciadas na literatura, como o da transgressão, o discurso político, o individualista e o do bode expiatório. Giglioli (1996) realiza um esforço semelhante, porém concentrado no exame do papel desempenhado pela mídia na investigação judicial de um caso concreto de corrupção política em Milão nos anos 1990. A importância das reflexões desenvolvidas pelo autor está em demonstrar como os enfoques utilizados pela imprensa servem à realização de uma lógica de mercado que precede, muitas vezes, a lógica do apoio político.

Silva e colaboradores (2005) buscam compreender, ainda no campo das análises do discurso, os sentidos sobre a corrupção construídos pelo jornal Folha de S.Paulo em um caso de corrupção envolvendo uma multinacional no campo alimentício. Considerada a escassez desse tipo de estudo em nosso país, o texto serve como um ponto de partida para novas pesquisas que aprofundem o exame das práticas discursivas em jornais, revistas, telejornais etc.

\section{QUADRO 8 O TRATAMENTO DA CORRUPÇÃO PELA MÍDIA, SEGUNDO A PESQUISA CIENTÍFICA}

\begin{tabular}{l|l|l} 
Narrativas & Construção e análise do discurso & $\begin{array}{l}\text { Breit (2010); Giglioli (1996); Silva e } \\
\text { colaboradores (2005) }\end{array}$ \\
\hline Função dos meios de comunicação & Simplificação da realidade & Barros Filho e Praça (2014)
\end{tabular}

Fonte: Elaborado pelos autores. 
Outra aproximação aos temas sobre corrupção apropriados pela mídia é encontrada em Barros Filho e Praça (2014). Os autores recorrem ao discurso filosófico e da ciência política para desfazer várias das simplificações que o veio jornalístico é pródigo em produzir, auxiliando a compreensão dos sentidos associados à corrupção.

\section{A PESQUISA SOBRE CORRUPÇÃO NO CASO BRASILEIRO E SUA INTERFACE COM A ADMINISTRAÇÃO PÚBLICA}

Percorridos os sentidos da pesquisa sobre corrupção, resta-nos perguntar quais particularidades a produção brasileira sobre a corrupção possui e quais suas conexões com a área de administração pública.

A primeira particularidade sobre os estudos realizados por autores brasileiros está no fato de que, ao contrário da produção internacional, concentrada em artigos científicos publicados em revistas com alto fator de impacto, eles são encontrados com maior frequência em ensaios e livros. Algumas obras surgiram nas últimas décadas, como a de Filgueiras (2008a), Avritzer e colaboradores (2008), Pinto (2011), Biason (2012b), Martins (2008) e Furtado (2015). A maior parte delas, entretanto, não tem origem na administração pública, mas na ciência política.

Fora dos livros, a circulação do tema em periódicos é bastante tímida. Uma consulta à base Spell revela como a produção científica brasileira sobre corrupção ainda é pequena na área da administração pública. Quando aplicamos o descritor corruption no seu campo de buscas somos confrontados com apenas 53 artigos - número que, em seguida, é reduzido drasticamente ao adicionarmos o filtro "administração pública" em "área do conhecimento". Relativamente ao número inicial, sobram apenas sete artigos, dos quais quatro tomam, de fato, a corrupção como tema central da investigação. Nesse cenário, sobressaem-se os textos de Brei (1996a, 1996b), que introduzem uma discussão mais geral sobre a corrupção a partir das suas correntes de pensamento, causas e consequências, o texto recente de Caldas, Costa e Pagliarussi (2016), que pensa a relação entre a corrupção e a composição dos gastos governamentais com saúde e educação no âmbito municipal, e o pequeno texto de Silva (1994).

A julgarmos por esses resultados, a produção científica no campo da administração pública brasileira precisa ser incrementada: não apenas no que diz respeito à amplitude temática, para acolher novas discussões, como, também, no tocante à natureza de suas abordagens, ainda estreitamente ligadas à ideia clássica de que a corrupção deve ser explicada no entrechoque entre os domínios público e privado.

A segunda particularidade sobre essa produção está no fato de que uma parte importante dela tem origem em centros de estudos sobre a corrupção, entre os quais podemos destacar o Centro de Referência do Interesse Público (Crip), da Universidade Federal de Minas Gerais, e o Centro de Estudos e Pesquisas sobre Corrupção (CEPC), da Universidade Estadual Paulista. Esses centros de estudos são responsáveis pela organização de encontros científicos que fomentam, direta e indiretamente, a produção de literatura nacional sobre o tema.

Por fim, a terceira particularidade que observamos nos estudos brasileiros sobre corrupção é de que, não obstante eles tenham se desenvolvido com bastante vigor ao longo da última década e venham experimentando, mais recentemente, sua efervescência no país, uma parte significativa de nossa produção intelectual se constitui a partir de um quadro referencial teórico estrangeiro.

Dessa forma, embora o avanço dos estudos mais gerais sobre corrupção no Brasil dê crédito à existência de uma literatura sobre o tema, é necessário que os agentes da pesquisa aperfeiçoem a construção de um pensamento brasileiro, especialmente no campo da administração pública, onde os estudos são, atualmente, escassos. 


\section{DESAFIOS E OPORTUNIDADES: UMA AGENDA PARA FUTURAS INVESTIGAÇÕES SOBRE A CORRUPÇÃO}

Quando lançamos nosso olhar sobre o modo como a pesquisa em administração pública se organiza na atualidade, observamos a existência de uma estreita relação entre ela e a agenda governamental. Significa dizer que as preocupações experimentadas na prática diária de governos locais, regionais e nacionais servem de catalizadores a pesquisas que serão desenvolvidas, adiante, no âmbito científico.

No caso da corrupção, a julgar pelo levantamento bibliográfico apresentado nos tópicos anteriores, somos levados a crer na prevalência de um estado no qual a atividade governamental não estimulou ainda, senão de maneira tímida, experimentações e explicações científicas para as dificuldades encontradas por administradores públicos em suas atividades cotidianas.

Um dos desafios a ser enfrentado, portanto, pelos estudos e investigações nesse campo consiste em estabelecer seu acoplamento à agenda governamental, de modo que lhes sejam assegurados um lugar ao lado da práxis administrativa.

Nesse contexto, o fortalecimento de uma agenda de pesquisa sobre corrupção reúne desafios e oportunidades que podem ser traduzidos em questões de pesquisa como as que apresentamos a seguir:

- Os estudos sobre corrupção produzidos na última década e que apoiam a ampliação do olhar cultural sobre esse tema são, de fato, recepcionados por entidades impregnadas da lógica racional - e.g., o Banco Mundial e o Fundo Monetário Internacional - segundo as quais a corrupção poderia ser explicada pelo modo como os agentes públicos realizam escolhas e maximizam o interesse privado?

- As estratégias ou práticas adotadas pela administração pública brasileira para combate à corrupção, especialmente no âmbito municipal, refletem a diversidade de concepções que a literatura científica possui sobre o tema do controle?

- A perspectiva sobre os altos custos da atividade de controle da corrupção, elaborada por Anechiarico e Jacobs (1996) no início dos anos 1990, permanece atual e é capaz de explicar as consequências que essas atividades produzem, mormente em países como o Brasil, nos quais estão em curso grandes operações de combate à corrupção?

- A percepção bastante difundida de que detentores de cargos eletivos (e.g., os agentes políticos) e detentores de cargos em comissão produzem mais corrupção que servidores efetivos (os quais ascenderam ao cargo de maneira meritocrática) se sustenta após realizadas pesquisas quantitativas com o número de expulsões, exonerações e desligamentos dos servidores públicos e sua conexão com as irregularidades por eles praticadas?

- O avanço de estudos científicos que destacam a prevalência do aspecto biológico na prática da corrupção, como aqueles realizados por Sobhani e Bechara (2011), deve ser levado adiante? Que impactos esses estudos poderiam ter no recrutamento de servidores públicos no futuro?

- O ceticismo demonstrado por Alberto Guerreiro Ramos (1983) perante a Comissão para o Desenvolvimento da Administração na América Latina, consistente na afirmação de que a corrupção vinha sendo compreendida, até a década de 1970, como um fenômeno "pintado com cores exageradas ou interpretado erroneamente pelos autores" é um retrato que ainda hoje encontramos na pesquisa científica?

- Como pensar a imbricação entre relações de poder, cultura organizacional e corrupção, especialmente no que diz respeito ao modo como esses fenômenos contribuem para formação de coalizões, laços de confiança e redes de ação coletiva necessárias às práticas de corrupção? 
É importante ressaltar que a consolidação de uma agenda de pesquisa não se esgota nos exemplos dados anteriormente. Ao contrário, ela tomará forma e ampliará seus horizontes sempre que o estudioso do tema puder extrair do conjunto de textos que compõe os sentidos da pesquisa um número de questões, problemas e hipóteses que justifiquem novas incursões sobre o objeto de estudo.

\section{CONSIDERAÇÕES FINAIS}

Revisitada ao longo deste artigo, a extensa literatura sobre corrupção não é homogênea: os resultados evidenciam que as preocupações existentes na pesquisa científica dão origem a sentidos da pesquisa sobre corrupção que são introdutórios, conceituais e fenomenológicos, paradigmáticos, e que dizem respeito, ainda, a percepção, causas, efeitos da corrupção, ou a seu controle e modo de apresentação pela mídia.

Esses sentidos atraem a atenção dos estudiosos de maneira assimétrica. Do parco ou quase inexistente número de artigos dedicados exclusivamente à revisão de literatura sobre a corrupção até a infinidade de textos que atacam suas causas, efeitos e percepção, o tema é abordado com interesses diferentes no meio acadêmico.

A superação dessa dificuldade exige o recorte e o enquadramento temático da produção científica - atitudes que favorecem o primeiro contato do pesquisador com o estado da arte e facilitam a organização desta extensa produção que, a despeito do seu avanço, não tem sido rigorosamente revisitada e agrupada.

Estudos quantitativos representariam, nesse sentido, uma estratégia para municiar o pesquisador da área da administração pública com dados que lhe permitam investigar o tema em outras direções. Para preencher o espaço deixado pela escassez de artigos existentes sobre o tema em nossa área, sugerimos a realização de buscas em bancos de dissertações e teses existentes em nosso país, a exemplo do que fizeram Sacramento e Pinho (2009).

A fim de avançarmos na compreensão das práticas de corrupção, é importante que valorizemos iniciativas que aprofundem também a análise do discurso associado a elas. Os estudos existentes nesse campo são raros e, em sua maioria, frutos de esforços isolados ou descontinuados de pesquisadores.

A ausência de material didático destinado ao ensino sobre a corrupção é outro ponto a ser trabalhado, razão pela qual iniciativas que estimulem a confecção de casos de ensino sobre corrupção, especialmente na administração pública, são bem-vindas.

De nossa parte, pretendemos haver prestado uma contribuição importante aos estudos de administração pública ao identificar os sentidos das pesquisas sobre corrupção e organizá-los a partir de seis eixos temáticos. Não se trata de uma contribuição definitiva, mas inicial, no sentido de que ela oferece ao pesquisador e estudioso das organizações públicas um ponto de partida para aprofundarse nos temas e discussões sobre corrupção realizados no meio científico. 


\section{REFERÊNCIAS}

ABRAMO, Cláudio W. Percepções pantanosas: a dificuldade de medir a corrupção. Novos Estudos Cebrap, n. 73, p. 33-37, 2005.

AGATIELLO, Osvaldo R. Corruption not an end. Management Decision, v. 48, n. 10, p. 1456-1468, 2010.

AIDT, Toke S. Corruption, institutions, and economic development. Oxford Review of Economic Policy, v. 25, n. 2, p. 271-291, 2009.

AIDT, Toke S. Economic analysis of corruption: a survey. The Economic Journal, v. 113, n. 491, p. F632-F652, 2003.

ANDERSEN, Thomas B. E-government as an anticorruption strategy. Information Economics and Policy, v. 21, n. 3, p. 201-210, 2009.

ANECHIARICO, Frank; JACOBS, James B. The pursuit of absolute integrity: how corruption control makes government ineffective. Chicago: The University of Chicago Press, 1996.

ARMSTRONG, Rebecca et al. 'Scoping the scope' of a cochrane review. Journal of Public Health, v. 33, n. 1, p. 147-150, 2011.

AVRITZER, Leonardo et al. (Org.). Corrupção: ensaios e críticas. Belo Horizonte: UFMG, 2008.

BALAFOUTAS, Loukas. Public beliefs and corruption in a repeated psychological game. Journal of Economic Behavior and Organization, v. 78, n. 1, p. 51-59, 2011.

BARDHAN, Pranab. Corruption and development: a review of issues. Journal of Economic Literature, v. 35, n. 3, p. 1320-1346, 1997.

BARR, Abigail; SERRA, Danila. Corruption and culture: an experimental analysis. Journal of Public Economics, v. 94, n. 11-12, p. 862-869, 2010.

BARROS FILHO, Clóvis de; PRAÇA, Sérgio. Corrupção: parceira degenerativa. Campinas: Papirus 7 Mares, 2014.

BERTOT, John C.; JAEGER, Paul T.; GRIMES, Justin M. Using ICTs to create a culture of transparency: e-government and social media as openness and anti-corruption tools for societies.
Government Information Quarterly, v. 27, n. 3, p. 264-271, 2010.

BHATTACHARYYA, Sambit; HODLER, Roland. Media freedom and democracy in the fight against corruption. European Journal of Political Economy, v. 39, p. 13-24, 2015.

BIASON, Rita de C. Questão conceitual: o que é corrupção? In: BIASON, Rita C. (Ed.). Temas de corrupção política. São Paulo: Balão Editorial, 2012a. p. 9-19.

BIASON, Rita de C. (Ed.). Temas de corrupção política. São Paulo: Balão Editorial, 2012b.

BOTELHO, Louise L. R.; CUNHA, Cristiano C. de A.; MACEDO, Marcelo. O método da revisão integrativa nos estudos organizacionais. Gestão e Sociedade, v. 5, n. 11, p. 121-136, 2011.

BREI, Zani A. A corrupção: causas, consequências e soluções para o problema. Rev. Adm. Pública, Rio de Janeiro, v. 30, n. 3, p. 13, 1996 .

BREI, Zani A. Corrupção: dificuldades para definição e para um consenso. Rev. Adm. Pública, Rio de Janeiro, v. 30, n. 1, p. 14, 1996 b.

BREIT, Eric. On the (re)construction of corruption in the media: a critical discursive approach. Journal of Business Ethics, v. 92, n. 4, p. 619-635, 2010.

BUDAK, Jelena; RAJH, Edo. Corruption as an obstacle for doing business in the Western Balkans: a business sector perspective. International Small Business Journal, v. 32, n. 2, p. 140-157, 2014.

CALDAS, Olavo V.; COSTA, Cristiano M.; PAGLIARUSSI, Marcelo S. Corrupção e composição dos gastos governamentais: evidências a partir do Programa de Fiscalização por Sorteios Públicos da Controladoria-Geral da União. Rev. Adm. Pública, Rio de Janeiro, v. 50, n. 2, p. 237-264, mar./abr. 2016.

CAMAJ, Lindita. The media's role in fighting corruption: media effects on governmental accountability. International Journal of Press/Politics, v. 18, n. 1, p. 21-42, 2013.

CARVALHO, José M. de. Quem transgride o quê? In: CARDOSO, Fernando H.; MOREIRA, Marcílio M. (Coord.). Cultura das transgressões no Brasil: lições da história. 2. ed. São Paulo: Saraiva, 2008. p. 69-94. 
DONG, Bin; DULLECK, Uwe; TORGLER, Benno. Conditional corruption. Journal of Economic Psychology, v. 33, n. 3, p. 609-627, 2011.

DREHER, Axel; KOTSOGIANNIS, Christos; MCCORRISTON, Steve. Corruption around the world: evidence from a structural model. Journal of Comparative Economics, v. 35, n. 3, p. 443-466, 2007.

FILGUEIRAS, Fernando. A corrupção do Estado: perspectivas teóricas e seu processo social. Utopia y Praxis Latinoamericana, v. 11, n. 34, p. 11-34, 2006.

FILGUEIRAS, Fernando. A tolerância à corrupção no Brasil: uma antinomia entre normas morais e prática social. Opinião Pública, v. 15, n. 2, p. 386-421, 2009.

FILGUEIRAS, Fernando. Corrupção, democracia e legitimidade. Belo Horizonte: UFMG, 2008a.

FILGUEIRAS, Fernando. Marcos teóricos da corrupção. In: AVRITZER, Leonardo et al. (Org.). Corrupção: ensaios e críticas. Belo Horizonte: UFMG, 2008b. p. 353-361.

FILGUEIRAS, Fernando; ARANHA, Ana L. M. Controle da corrupção e burocracia da linha de frente: regras, discricionariedade e reformas no Brasil. Dados: Revista de Ciências Sociais, v. 54, n. 2, p. 349-387, 2011.

FROST, Jetta; TISCHER, Sarah. Unmasking collective corruption: the dynamics of corrupt routines. European Management Review, v. 11, n. 3-4, p. 191-207, 2014.

FURTADO, Lucas R. As raízes da corrupção no Brasil: estudo de casos e lições para o futuro. Belo Horizonte: Fórum, 2015.

GIGLIOLI, Pier P. Political corruption and the media: the Tangentopoli affair. International Social Science Journal, v. 48, n. 3, p. 381-394, 1996.

GOEL, Rajeev K.; NELSON, Michael A. Causes of corruption: history, geography and government. Journal of Policy Modeling, v. 32, n. 4, p. 433-447, 2010 .

GONG, Ting; WANG, Shiru. Indicators and implications of zero tolerance of corruption: the case of Hong Kong. Social Indicators Research, v. 112, n. 3, p. 569-586, 2013.
HEIDENHEIMER, Arnold J. The topography of corruption: explorations in a comparative perspective. International Social Science Journal, v. 48, n. 3, p. 337-347, 1996.

JOHNSTON, Michael. Syndromes of corruption: wealth, power, and democracy. Cambridge: Cambridge University Press, 2005.

JOHNSTON, Michael. The search for definitions: the vitality of politics and the issue of corruption. International Social Science Journal, v. 48, n. 3, p. 321-335, 1996.

JUDGE, William Q.; MCNATT, Brian; XU, Weichu. The antecedents and effects of national corruption: a meta-analysis. Journal of World Business, v. 46, n. 1, p. 93-103, 2010.

KARMANN, Tobias et al. Entrepreneurial orientation and corruption. Journal of Business Ethics, v. 133, n. 2, p. 223-234, 2016.

KLITGAARD, Robert E. A corrupção sob controle. Rio de Janeiro: Jorge Zahar, 1994.

LEE, Wang-Sheng; GUVEN, Cahit. Engaging in corruption: the influence of cultural values and contagion effects at the microlevel. Journal of Economic Psychology, v. 39, p. 287-300, 2013.

LIO, Mon-Chi; LIU, Meng-Chun; OU, Yi-Pey. Can the internet reduce corruption? A cross-country study based on dynamic panel data models. Government Information Quarterly, v. 28, n. 1, p. 47-53, 2011.

MACHADO, Julio C. Um estudo semântico enunciativo da corrupção em dicionários e documentos governamentais. Alfa: Revista de Linguística, v. 54, n. 1, p. 145-175, 2010.

MARTINS, José A. Corrupção. São Paulo: Globo, 2008.

MÉNY, Yves. Fin de siècle corruption: change, crisis and shifting values. International Social Science Journal, v. 48, n. 3, p. 309-320, 1996.

MÉON, Pierre-Guillaume; WEILL, Laurent. Is corruption an efficient grease? World Development, v. 38, n. 3, p. 244-259, 2010.

MILLER, William L. Corruption and corruptibility. World Development, v. 34, n. 2, p. 371-380, 2006. 
MISHRA, Ajit. Persistence of corruption: some theoretical perspectives. World Development, v. 34, n. 2, p. 349-358, 2006.

NYE, Joseph S. Corruption and political development: a cost-benefit analysis. The American Political Science Review, v. 61, n. 2, p. 417-427, 1967.

OLKEN, Benjamin A. Corruption perceptions vs. corruption reality. Journal of Public Economics, v. 93, n. 7-8, p. 950-964, 2009.

PETROU, Andreas P.; THANOS, Ioannis C. The "grabbing hand" or the "helping hand" view of corruption: evidence from bank foreign market entries. Journal of World Business, v. 49, n. 3, p. 444-454, 2014.

PHILP, Mark. Defining political corruption. Political Studies, v. 45, n. 3, p. 436-460, 1997.

PINTO, Céli R. J. A banalidade da corrupção: uma forma de governar o Brasil. Belo Horizonte: UFMG, 2011.

POESCHL, Gabrielle; RIBEIRO, Raquel. Ancoragens e variações nas representações sociais da corrupção. Análise Social, v. 45, n. 196, p. 419-445, 2010.

PRAÇA, Sérgio. Corrupção e reforma institucional no Brasil, 1988-2008. Opinião Pública, v. 17, n. 1, p. 137-162, 2011.

RAMOS, Alberto G. A nova ignorância e o futuro da administração pública na América Latina. Rev. Adm. Pública, Rio de Janeiro, v. 4, n. 2, p. 32-65, 1983.

RIBEIRO, Renato J. Da política da corrupção. In: RIBEIRO, Renato J. A sociedade contra o social: o alto custo da vida pública no Brasil. São Paulo: Companhia das Letras, 2000. p. 162-190.

ROBERTS, John. The 'subject' of corruption. Critical Perspectives on Accounting, v. 28, p. 82-88, 2015.

ROMAN, Alexandru V.; MILLER, Hugh T. Building social cohesion: family, friends, and corruption. Administration \& Society, v. 46, n. 7, p. 775-795, 2014.

ROSE-ACKERMAN, Susan. Corruption and government: causes, consequences, and reform. Cambridge: Cambridge University Press, 1999.
ROSE-ACKERMAN, Susan. "Grand" corruption and the ethics of global business. Journal of Banking and Finance, v. 26, n. 9, p. 1889-1918, 2002.

ROSENBLATT, Valerie. Hierarchies, power inequalities, and organizational corruption. Journal of Business Ethics, v. 111, n. 2, p. 237-251, 2012.

RUMRILL, Phillip D.; FITZGERALD, Shawn M.; MERCHANT, William R. Using scoping literature reviews as a means of understanding and interpreting existing literature. Work, v. 35, n. 3, p. 399, 2010.

SACRAMENTO, Ana R. S.; PINHO, José A. G. A Produção Acadêmica Brasileira sobre Corrupção em Administração Pública. In: ENANPAD, 33, 2009, São Paulo. Anais... São Paulo: Anpad, 2009. p. 1-16.

SAH, Raaj. Corruption across countries and regions: some consequences of local osmosis. Journal of Economic Dynamics and Control, v. 31, n. 8, p. 25732598, 2007.

SANTOS, Renato A. dos; GUEVARA, Arnoldo J. de H.; AMORIM, Maria C. S. Corrupção nas organizações privadas: análise da percepção moral segundo gênero, idade e grau de instrução. Rausp: Revista de Administração da Universidade de São Paulo, v. 48, n. 1, p. 53, 2013.

SILVA, Maurício. Corrupção: tentativa de uma definição funcional. Rev. Adm. Pública, Rio de Janeiro, v. 28, n. 1, p. 18-23, 1994.

SILVA, Paulo J. et al. A ação corrupta em uma organização multinacional: uma análise sob a ótica da abordagem construcionista. REAd. Revista Eletrônica de Administração, v. 11, n. 6, p. 1-27, 2005

SOBHANI, Mona; BECHARA, Antoine. A somatic marker perspective of immoral and corrupt behavior. Social Neuroscience, v. 6, n. 5-6, p. 640-653, 2011.

TAY, Louis; HERIAN, Mitchel N.; DIENER, Ed. Detrimental effects of corruption and subjective wellbeing: whether, how, and when. Social Psychological and Personality Science, v. 5, n. 7, p. 751-759, 2014.

THEOBALD, Robin. So what really is the problem about corruption? Third World Quarterly, v. 20, n. 3, p. 491-502, 1999.

TORSELLO, Davide; VENARD, Bertrand. The anthropology of corruption. Journal of Management Inquiry, v. 25, n. 1, p. 34-54, 2016. 
TRUEX, Rory. Corruption, attitudes, and education: survey evidence from Nepal. World Development, v. 39, n. 7, p. 1133-1142, 2011.

WARREN, Mark E. La democracia contra la corrupción. Revista Mexicana de Ciencias Políticas $y$ Sociales, n. 193, p. 109-141, 2005.
WARREN, Mark E. What does corruption mean in a democracy? American Journal of Political Science, v. 48, n. 2, p. 328-343, 2004.

WILLIAMS, Robert. New concepts for old? Third World Quarterly, v. 20, n. 3, p. 503-513, 1999.

\section{Sílvio César Zákhia Marani}

Mestre em administração pública (Ufla), graduou-se em filosofia pela Faculdade de Filosofia e Ciências Humanas da Universidade Federal de Minas Gerais (Fafich/UFMG) e direito pela Faculdade de Direito Milton Campos (FDMC).E-mail: silvio.zakhia@outlook.com.

\section{Mozar José de Brito}

Doutor em administração (USP) e pesquisador CNPq e Fapemig, é professor titular da Universidade Federal de Lavras (Ufla) e membro permanente do seu Programa de Pós-Graduação em Administração (PPGA).

E-mail: mozarbrito@gmail.com.

\section{Gustavo Costa de Souza}

Doutor em políticas públicas (IE/UFRJ), professor adjunto do Departamento de Administração e Economia da Universidade Federal de Lavras (DAE/Ufla) e membro permanente do Programa de Pós-graduação em Administração Pública (PPGAP/DAE/Ufla). E-mail: gustavocosta.ufla@gmail.com.

\section{Valéria da Glória Pereira Brito}

Doutora em administração (Cepead/Face/UFMG), é professora associada da Universidade Federal de Lavras (Ufla) e membro permanente do seu Programa de Pós-Graduação em Administração (PPGA)

E-mail:vgpbrito@gmail.com. 